Published in final edited form as:

Curr Opin Pulm Med. 2016 March ; 22(2): 138-143. doi:10.1097/MCP.0000000000000248.

\title{
Pulmonary Health Effects of Air Pollution
}

\author{
Ozlem Kar Kurt ${ }^{1,2}$, Jingjing Zhang ${ }^{1,3}$, and Kent E. Pinkerton ${ }^{1}$ \\ ${ }^{1}$ Center for Health and the Environment, University of California, Davis, Davis, CA USA \\ ${ }^{2}$ Hacettepe University, Department of Chest Diseases, Unit of Occupational Medicine, Ankara, \\ Turkey \\ ${ }^{3}$ Western China School of Public Health, Department of Occupational and Environmental Health, \\ Sichuan University, Chengdu, China
}

\begin{abstract}
Purpose of the review-Air pollution continues to be a major public health concern affecting nine out of ten individuals living in urban areas worldwide. Exposure to air pollution is the ninth leading risk factor for cardiopulmonary mortality. The aim of this review is to examine the current literature for the most recent updates on health effects of specific air pollutants and their impact on asthma, chronic obstructive pulmonary disease (COPD), lung cancer and respiratory infection.
\end{abstract}

Recent findings-A total of 53 publications were reviewed to establish new insights as to how air pollution is associated with pulmonary morbidity and mortality. Considerable past evidence suggests that air pollution is an important factor that enhances pulmonary disease, while also causing greater harm in susceptible populations, such as children, the elderly and those of low socio-economic status worldwide. Asthma, COPD, lung cancer and respiratory infections all seem to be exacerbated due to exposure to a variety of environmental air pollutants with the greatest effects due to particulate matter (PM), ozone and nitrogen oxides. New publications reviewed reaffirm these findings.

Summary-Continued vigilence will be essential to lessen the effects of air pollution on human health and pulmonary disease. Cooperation at a multi-national level will be required on the part of governments, industry, energy-based enterprises and the public working together to solve our air quality issues at the local, national and global level.

\section{Keywords}

particulate matter; ozone; criteria pollutants

\section{Introduction}

Ambient air pollution is a major global public health problem, affecting both developing and developed countries. Many developing countries derive energy from natural, inexpensive

Correspondence: Kent E. Pinkerton, Ph.D., Center for Health and the Environment, University of California, Davis, One Shields Avenue, Davis, CA 95616, Tel: 530-752-8334, kepinkerton@ucdavis.edu.

Conflicts of interest

The authors have no conflicts of interest. 
sources for industrial, commercial and living purposes, but do not have sufficient technologies to mitigate potential air pollution arising from these energy sources. According to the World Health Organization (WHO) Ambient Air Pollution database, derived from measurements taken in 1600 cities in 91 countries, almost nine out of ten individuals living in urban areas are affected by air pollution [1]. Exposure to outdoor air pollution is the ninth leading risk factor for mortality, and outdoor air pollution is responsible for 3.2 million deaths each year [2]. Recent studies show that exposure to air pollution is associated with acute and chronic cardiopulmonary mortality and all cause mortality [3-5]. The aim of this review is to examine the current literature for the most recent updates on health effects of specific air pollutants and their impact on asthma, chronic obstructive pulmonary disease (COPD), lung cancer and respiratory infection. A total of 53 publications were assessed and included in the review to relay the current state of knowledge as to how air pollution is associated with pulmonary morbidity and mortality. The included literatüre covers epidemiologic, controlled human, and animal toxicologic studies.

\section{Components of modern day ambient air pollution}

Current air pollution frequently found in urban areas is a dynamic and complex mixture of both man-made (anthropogenic) pollutants and natural sources. Six common ambient air pollutants are particulate matter $(\mathrm{PM})$, ozone $\left(\mathrm{O}_{3}\right)$, sulphur dioxide $\left(\mathrm{SO}_{2}\right)$, nitrogen oxides $\left(\mathrm{NO}_{\mathrm{x}}\right)$, carbon monoxide $(\mathrm{CO})$, and lead. In the United States, these primary air contaminants are classified as "criteria" pollutants by the Environmental Protection Agency. National Ambient Air Quality Standards have been set for each of these pollutants, by law, which must undergo an extensive literature review update every five years to ensure adequate health protection of the public. These same pollutants are found worldwide to differing degrees, but all are associated with adverse human health, as discussed below.

A recent review of global premature mortality due to outdoor air pollution by Lelieveld et al., found that fine $\mathrm{PM}\left(\mathrm{PM}_{2.5}\right)$ is estimated to cause 3.3 million deaths per year worldwide[6]. PM is mainly formed through industrial processes and traffic-related sources (gasoline and diesel), coal and oil fuel combustion, farming and road construction. PM is commonly subdivided into three size classifications: coarse particles with diameters 2.5 to $10 \mu \mathrm{m}\left(\mathrm{PM}_{10}\right)$, fine particles with diameters less than $2.5 \mu \mathrm{m}\left(\mathrm{PM}_{2.5}\right)$, ultrafine particles with diameters less than $0.1 \mathrm{~mm}$ (UF). Traffic-related sources of PM are thought to be responsible for approximately $20 \%$ of air pollution-related mortality in Germany, the United Kingdom and the United States [6]. Coarse particles are often caused by disturbances of crustal materials (dust) and are a problem in the Middle East and other desert areas due to dust storms. Throughout the world residential and commercial energy use is linked to premature mortality, but is especially prevalent in Asia, where biofuel used for heating and cooking produces high levels of fine PM[6]. The potency of PMs in causing an adverse health impact is dependent, in part, on their deposition in the airways and the composition of their surface components[7]

As urban centers increase in size and the global climate continues to change, it is estimated that ground level ozone (ozone smog) will become an even greater of health hazard. Ozone smog forms when nitrogen oxides and volatile organic compounds from vehicle, power, and 
other sources mix with sunlight and heat. As such, as the temperature increases, ozone formation increases. Other criteria pollutants, such as $\mathrm{SO}_{2}, \mathrm{NO}_{\mathrm{X}}$, and $\mathrm{CO}$, which are produced by fossil fuel combustion will continue to contribute to air pollution in large urban areas as well, especially in dense cities, such as those in Asia.

\section{Influences in the distribution of today's air pollution}

Indoor air pollution can also be a source of exposure of exposure to air contaminants, made up of multiple pollutants, including environmental or secondhand smoke, combustion of solid fuels for home heating and cooking, formaldehyde, volatile organic compounds, and intrusion of ambient air pollution. A primary source for global household air pollution is the incomplete combustion of biofuels resulting in high levels of chemical components such as carbon monoxide, sulfur oxides, nitrogen oxides, particulates, benzene, formaldehyde, polyaromatic compounds, arsenic, and lead. Its relative contribution to human exposure can be relatively high, based on the time spent indoors.

A more recent concern has been the atmospheric findings of transport of PM, ozone and even infectious components over large distances, including dust from Mongolia to the Western United States as well as Saharan dust crossing the Atlantic to deposit in countries of the Carribean. Climate change and air quality are also closely related. Recent data suggest that climate change is associated with elevations of both ozone and PM in the atmosphere[8].

\section{Pulmonary Heath Effects}

\section{4.a. Lifestages for susceptibility to air pollution}

Children and adolesents are more susceptable to the effects of air pollution than adults. The human respiratory system develops in utero to adolescence. Although lung function development continues in girls until their late teens and in boys until their early $20 \mathrm{~s}$, from birth to approximatley 6 years of age represents the greatest period of postnatal development, with formation of more than $80 \%$ of new alveoli following birth. Susceptibility to the adverse health effects of environmental and chemical toxicants may vary in different lung development stages. Environmental exposures can alter the development of both immune function and lung mechanics, including lung injury and repair [9]. Due to smaller airways, immature detoxification and metabolic systems, as well as frequent exposure to outdoor air, children are often more susceptible to airway toxicants than adults [10]. The good news is that long-term improvements in air quality have recently been shown to result in statistically and clinically significant positive effects on lungfunction growth in children and also adolescents from 11 to 15 years of age reported by Gauderman and collegues in 2015 [11].

The elderly population has also been shown to be more susceptable to inflammation and respiratory complications due to air pollution. In the elderly, particle clearance might be less efficient or impaired by other dysfunctions. 


\section{4.b. Asthma}

A 2015 study by Carosino et al demonstrated using an animal model that exposure to PM exacerbates allergic inflammation in the lung [12]. Ozone has also been shown to cause oxidative stress, inflammatory responses and immunologic disease in laboratory animals [13]. Li et al. have demonstrated that $\mathrm{SO}_{2}$ affects the airway inflammatory and immune responses of asthmatic rats and enhances their susceptibility by aggravating inflammatory responses in the lung [14].

Exposure to air pollutants can lead not only to inflammation, but also changes in lung function. In 2013 Rice et al using The Framingham Heart Study found short-term exposure to $\mathrm{PM}_{2.5}$, ozone, and $\mathrm{NO}_{2}$ were associated with a lower FEV1 and FVC in nonsmoking adults [15]. In children Mölter et al. have reported that lifetime exposure to $\mathrm{PM}_{10}$ and $\mathrm{NO}_{2}$ may be associated with reduced growth in FEV1 [16]. A longitudinal cohort study reported in 2015 showed that long-term $\mathrm{NO}_{2}$ and $\mathrm{PM}_{10}$ exposure decreased lung function parameters (FEV1, FVC) [17]. Two studies of Chinese schoolchildren in 2013 and 2014, found longterm exposure to ambient air pollution was associated with a number of adverse effects, such as wheezing, cough or phlegm. Of interest was that $\mathrm{PM}_{10}$ may be the most relevant pollutant associated with adverse effects as well as with impaired lung function $[18,19]$.

A large body of evidence also demonstrates an association between short-term exposure to air pollutants and the incidence of asthma exacerbations and hospital admissions. Short-term exposure to ozone has been shown to be significantly associated with increased hospitalizations in children [20]. Ierodiakonou and colleagues also recently found exposure to ambient air pollutants was associated with reduced lung function and increased airway responsiveness in asthmatic children [21].

Poor air quality due to high levels of ozone has been shown to not only contribute to the exacerbation of asthma, but to also be a cause in the development of asthma [22]. It is less clear what are the effects of other sources of air pollutants in asthma development, such as traffic-related emissions. However, a systematic review published in 2015 suggests that exposure in early childhood to traffic-related air pollution (TRAP) containing $\mathrm{PM}_{2.5}$ is associated with an increased incidence of asthma up to the age of 12 years [23]. However, the European Study of Cohorts for Air Pollution Effects (ESCAPE) found conflicting findings of no association between $\mathrm{PM}_{2.5}, \mathrm{PM}_{10}$ or $\mathrm{NO}_{2}$ and the prevalence of childhood asthma [24]. This difference might be due to study design and/or multiple other causes of asthma in children. A Korean study published in 2015 demonstrated long-term exposure to TRAP may be associated with an increased risk of asthma, allergic sensitization and decreased lung function in schoolchildren depending on the proximity of their residence to a major road [25]. A study from Japan in 2014 of 10,069 children aged 6-9 years found TRAP associated with development of asthma [26]. Finally, in a recent review article of 2014, Trevor et al. shows a consistent relationship between biomass smoke and asthma symptoms [27].

Air pollution leading to adult-onset asthma still remains unclear. However, Young et al. in 2014 reported that $\mathrm{PM}_{2.5}$ exposure increases the risk of developing asthma in adult women [4]. In addition, a large 2015 European study of 23,704 adults followed ten years from eight 
countries to show an association between TRAP $\left(\mathrm{PM}_{2.5}\right)$ exposure and increased asthma incidence in adults [28].

\section{4.c. COPD}

Chronic obstructive pulmonary disease (COPD) is most commonly associated with smoking, however, a new study of 2015 estimated the prevalence of COPD among nonsmokers varies from $1.1 \%$ to $40 \%$ in different countries [29]. The high incidence of COPD among nonsmokers is in large measure associated with indoor air pollution from biomass combustion [30] and second-hand tobacco smoke. A recent 2014 study demonstrated that improving air quality in the home decreases the incidence of COPD [31]. Other risk factors for COPD include occupational exposures and outdoor air pollution. The fraction of COPD attributable to occupation in a study of 2015 was $31.1 \%$ among nonsmoking workers [29]. There are some epidemiologic studies showing an association between outdoor air pollution and COPD from both developing and developed countries [3, 32]. A 2014 meta-analysis study reported that outdoor air pollution was associated with an increase of COPD incidence and prevalence [33]. In the same review, the authors mentioned that a $10 \mu \mathrm{g} / \mathrm{m}^{3}$ increase of $\mathrm{PM}_{10}$ in outdoor air can induce significant acute exacerbations of and mortality from COPD. A recent European review suggests a role of ambient air pollution and COPD[34]. Tsai SS. in 2013 that there is a strong relationshio between air pollution and acute exacerbations of COPD-related hospital admission[35]. However, two cohort studies in 2014 and 2015 demonstrate limited evidence of associations between outdoor air pollution and COPD incidence[36, 37].

\section{4.d. Lung Cancer}

Cigarette smoking is considered the most important cause of lung cancer. However, cigarette smoking is not the sole cause for lung cancer; additional risk factors include environmental and occupational exposures. Yu et al. in a study published in 2015 found somatic genomic mutations attributed to household air pollution (associated with coal combustion) in tumor and adjacent normal lung tissues and peripheral blood samples from 164 patients with previously untreated non-small cell lung cancer (NSCLC) compared to patients also with NSCLC from other regions with low levels of household air pollution (coal combustion) [38]. In October 2013, the International Agency for Research on Cancer (IARC) accepted outdoor air pollution and related PM as a class I human carcinogen based on data from human, animal and mechanistic studies[39]. Concurrent epidemiological studies in 2013 and 2014 indicate a positive correlation between air pollutants and lung cancer after adjustment for cigarette smoking [40, 41]. A European study also reported an association between incidence of adenocarcinoma and air pollution [41]. A recent 2015 meta-analysis shows that ambient exposure to nitrogen oxides, $\mathrm{SO}_{2}$, and $\mathrm{PM}_{2.5}$ from vehicle emissions significantly increases the risk of lung cancer [42]. Other studies also report that $\mathrm{NO}_{2}$ exposures are positively associated with lung cancer risk [41, 43, 44] and have the strongest associations with all-cause mortality and lung cancer [45]. As with $\mathrm{PM}_{2.5}$, positive correlations are reported based on a wide variety studies [46, 47]. A meta-analysis found that for each $10 \mu \mathrm{g} / \mathrm{m}^{3}$ increase in $\mathrm{PM}_{2.5}$, a meta-relative risk for lung cancer of 1.09 occurred [48]. In a case-control study from Canada, a mixed exposure to $\mathrm{PM}_{2.5}$ and $\mathrm{NO}_{2}$ was related with a larger risk for adenocarcinomas compared with other cancer subtypes 
[49]. In a recent study and review in 2012 and 2015 found professional drivers exposed to diesel engine exhaust have an elevated risk of lung cancer [50, 51].

\section{4.e. Respiratory infections}

Only a limited number of studies have examined the relationship between air pollution and respiratory infections. Vulnerable populations appear to be children, the eldery and people with chronic illness. Two recent epidemiological studies published in 2012 and 2014 demonstrate associations between short-term air pollution (traffic-related PM, ozone and organic carbon-based $\mathrm{PM}_{2.5}$ ), enhanced respiratory infection symptoms and increased emergency department visits by children $[52,53]$.

\section{Conclusions}

Concern for air pollution and its health implications continue to be a world-wide problem today. Air pollution remains a complex mixture of anthropogenic pollutants and natural sources. Of the six pollutants, PM and ozone represent the most widespread health threats for cardiopulmonary disease. Air pollution once thought of as purely a local or regional problem, now is recognised as a global issue with potential long distance atmospheric transport. Air pollution is an important contributor to respiratory complications, especially for developing countries who use biomass fuels and coal for heating and cooking in the home. It is essential that local, national and global efforts are undertaken by government, industry and the private sector to lessen the burden of air pollution to provide better respiratory health protection for everyone.

\section{Acknowledgements}

The authors acknowledge the following sources of support which provided the basis for our literature review: NIOSH OHO7550, P30 ES023513 and P51 OD011107.

Financial support and sponsorship

OKK is a Physician-Scientist Fellow funded under a training grant from Hacettepe University, Unit of Scientific Research Projects Coordination, Ankara, Turkey. JJZ is supported as a School of Public Health Fellow by the Chinese Scholarship Council (CSC) of China.

\section{References}

[1]**. World Health Organization. Ambient Air Pollution Database. WHO; Geneva, Switzerland: 2014. http://www.iarc.fr/en/media-centre/iarcnews/pdf/pr221_E.pdf [December 2015]

[2]. Lim SS, Vos T, Flaxman AD, et al. A comparative risk assessment of burden of disease and injury attributable to 67 risk factors and risk factor clusters in 21 regions, 1990-2010: a systematic analysis for the Global Burden of Disease Study 2010. Lancet. 2012; 380:2224-2260. [PubMed: 23245609]

[3]. Andersen ZJ, Hvidberg M, Jensen SS, et al. Chronic obstructive pulmonary disease and long-term exposure to traffic-related air pollution: a cohort study. Am J Respir Crit Care Med. 2011; 183:455-461. [PubMed: 20870755]

[4]. Gan WQ, Koehoorn M, Davies HW, et al. Long-term exposure to traffic-related air pollution and the risk of coronary heart disease hospitalization and mortality. Environ Health Perspect. 2011; 119:501-507. [PubMed: 21081301] 
[5]. Young MT, Sandler DP, DeRoo LA, et al. Ambient air pollution exposure and incident adult asthma in a nationwide cohort of U.S. women. Am J Respir Crit Care Med. 2014; 190:914-921. [PubMed: 25172226]

[6]**. Lelieveld J, Evans JS, Fnais M, et al. The contribution of outdoor air pollution sources to premature mortality on a global scale. Nature. 2015; 525:367-371. [PubMed: 26381985]

[7]. Stanek LW, Brown JS, Stanek J, et al. Air Pollution Toxicology-A Brief Review of the Role of the Science in Shaping the Current Understanding of Air Pollution Health Risks. Toxicological Sciences. 2011; 120:S8-S27. [PubMed: 21147959]

[8]. Rice MB, Thurston GD, Balmes JR, Pinkerton KE. Climate change. A global threat to cardiopulmonary health. Am J Respir Crit Care Med. 2014; 189:512-519. [PubMed: 24400619]

[9]. Martino D, Prescott S. Epigenetics and prenatal influences on asthma and allergic airways disease. Chest. 2011; 139:640-647. [PubMed: 21362650]

[10]. Pinkerton KE, Joad JP. Influence of air pollution on respiratory health during perinatal development. Clin Exp Pharmacol Physiol. 2006; 33:269-272. [PubMed: 16487273]

[11]**. Gauderman WJ, Urman R, Avol E, et al. Association of improved air quality with lung development in children. N Engl J Med. 2015; 372:905-913. [PubMed: 25738666]

[12]. Carosino CM, Bein KJ, Plummer LE, et al. Allergic airway inflammation is differentially exacerbated by daytime and nighttime ultrafine and submicron fine ambient particles: heme oxygenase-1 as an indicator of PM-mediated allergic inflammation. J Toxicol Environ Health A. 2015; 78:254-266. [PubMed: 25679046]

[13]. Wiegman CH, Li F, Clarke CJ, et al. A comprehensive analysis of oxidative stress in the ozoneinduced lung inflammation mouse model. Clin Sci (Lond). 2014; 126:425-440. [PubMed: 24040961]

[14]. Li R, Kou X, Tian J, et al. Effect of sulfur dioxide on inflammatory and immune regulation in asthmatic rats. Chemosphere. 2014; 112:296-304. [PubMed: 25048919]

[15]. Rice MB, Ljungman PL, Wilker EH, et al. Short-term exposure to air pollution and lung function in the Framingham Heart Study. Am J Respir Crit Care Med. 2013; 188:1351-1357. [PubMed: 24200465]

[16]. Molter A, Agius RM, de Vocht F, et al. Long-term exposure to PM10 and NO2 in association with lung volume and airway resistance in the MAAS birth cohort. Environ Health Perspect. 2013; 121:1232-1238. [PubMed: 23777813]

[17]. Adam M, Schikowski T, Carsin AE, et al. Adult lung function and long-term air pollution exposure. ESCAPE: a multicentre cohort study and meta-analysis. Eur Respir J. 2015; 45:38-50. [PubMed: 25193994]

[18]. Gao Y, Chan EY, Li LP, et al. Chronic effects of ambient air pollution on lung function among Chinese children. Arch Dis Child. 2013; 98:128-135. [PubMed: 23235891]

[19]. Gao Y, Chan EY, Li L, et al. Chronic effects of ambient air pollution on respiratory morbidities among Chinese children: a cross-sectional study in Hong Kong. BMC Public Health. 2014; 14:105. [PubMed: 24484614]

[20]*. Sheffield PE, Zhou J, Shmool JL, Clougherty JE. Ambient ozone exposure and children's acute asthma in New York City: a case-crossover analysis. Environ Health. 2015; 14:25. [PubMed: 25889205]

[21]**. Ierodiakonou D, Zanobetti A, Coull BA, et al. Ambient air pollution, lung function, and airway responsiveness in asthmatic children. J Allergy Clin Immunol. 2015

[22]. McConnell R, Berhane K, Gilliland F, et al. Asthma in exercising children exposed to ozone: a cohort study. Lancet. 2002; 359:386-391. [PubMed: 11844508]

[23]. Bowatte G, Lodge C, Lowe AJ, et al. The influence of childhood traffic-related air pollution exposure on asthma, allergy and sensitization: a systematic review and a meta-analysis of birth cohort studies. Allergy. 2015; 70:245-256. [PubMed: 25495759]

[24]. Molter A, Simpson A, Berdel D, et al. A multicentre study of air pollution exposure and childhood asthma prevalence: the ESCAPE project. Eur Respir J. 2015; 45:610-624. [PubMed: 25323237] 
[25]. Jung DY, Leem JH, Kim HC, et al. Effect of Traffic-Related Air Pollution on Allergic Disease: Results of the Children's Health and Environmental Research. Allergy Asthma Immunol Res. 2015; 7:359-366. [PubMed: 25936911]

[26]. Yamazaki S, Shima M, Nakadate T, et al. Association between traffic-related air pollution and development of asthma in school children: cohort study in Japan. J Expo Sci Environ Epidemiol. 2014; 24:372-379. [PubMed: 24619296]

[27]. Trevor J, Antony V, Jindal SK. The effect of biomass fuel exposure on the prevalence of asthma in adults in India - review of current evidence. J Asthma. 2014; 51:136-141. [PubMed: 24164361]

[28]*. Jacquemin B, Siroux V, Sanchez M, et al. Ambient air pollution and adult asthma incidence in six European cohorts (ESCAPE). Environ Health Perspect. 2015; 123:613-621. [PubMed: 25712593]

[29]. Bang KM. Chronic obstructive pulmonary disease in nonsmokers by occupation and exposure: a brief review. Curr Opin Pulm Med. 2015; 21:149-154. [PubMed: 25590955]

[30]. Gordon SB, Bruce NG, Grigg J, et al. Respiratory risks from household air pollution in low and middle income countries. Lancet Respir Med. 2014; 2:823-860. [PubMed: 25193349]

[31]. Zhou Y, Zou Y, Li X, et al. Lung function and incidence of chronic obstructive pulmonary disease after improved cooking fuels and kitchen ventilation: a 9-year prospective cohort study. PLoS Med. 2014; 11:e1001621. [PubMed: 24667834]

[32]. Lam KB, Yin P, Jiang CQ, et al. Past dust and GAS/FUME exposure and COPD in Chinese: the Guangzhou Biobank Cohort Study. Respir Med. 2012; 106:1421-1428. [PubMed: 22795505]

[33]*. Song Q, Christiani DC, XiaorongWang Ren J. The global contribution of outdoor air pollution to the incidence, prevalence, mortality and hospital admission for chronic obstructive pulmonary disease: a systematic review and meta-analysis. International journal of environmental research and public health. 2014; 11:11822-11832. [PubMed: 25405599]

[34]. Schikowski T, Mills IC, Anderson HR, et al. Ambient air pollution: a cause of COPD? Eur Respir J. 2014; 43:250-263. [PubMed: 23471349]

[35]. Tsai SS, Chang CC, Yang CY. Fine particulate air pollution and hospital admissions for chronic obstructive pulmonary disease: a case-crossover study in Taipei. International journal of environmental research and public health. 2013; 10:6015-6026. [PubMed: 24284359]

[36]. Schikowski T, Adam M, Marcon A, et al. Association of ambient air pollution with the prevalence and incidence of COPD. Eur Respir J. 2014; 44:614-626. [PubMed: 24488569]

[37]. Atkinson RW, Carey IM, Kent AJ, et al. Long-term exposure to outdoor air pollution and the incidence of chronic obstructive pulmonary disease in a national English cohort. Occup Environ Med. 2015; 72:42-48. [PubMed: 25146191]

[38]. Yu XJ, Yang MJ, Zhou B, et al. Characterization of Somatic Mutations in Air Pollution-Related Lung Cancer. EBioMedicine. 2015; 2:583-590. [PubMed: 26288819]

[39]. Anderson DS, Patchin ES, Silva RM, et al. Influence of Particle Size on Persistence and Clearance of Aerosolized Silver Nanoparticles in the Rat Lung. Toxicological Sciences. 2015; 144:366-381. [PubMed: 25577195]

[40]*. Loomis D, Huang W, Chen G. The International Agency for Research on Cancer (IARC) evaluation of the carcinogenicity of outdoor air pollution: focus on China. Chin J Cancer. 2014; 33:189-196. [PubMed: 24694836]

[41]. Raaschou-Nielsen O, Andersen ZJ, Beelen R, et al. Air pollution and lung cancer incidence in 17 European cohorts: prospective analyses from the European Study of Cohorts for Air Pollution Effects (ESCAPE). Lancet Oncol. 2013; 14:813-822. [PubMed: 23849838]

[42]. Chen G, Wan X, Yang G, Zou X. Traffic-related air pollution and lung cancer: A meta-analysis. Thorac Cancer. 2015; 6:307-318. [PubMed: 26273377]

[43]. Villeneuve PJ, Jerrett M, Brenner D, et al. A case-control study of long-term exposure to ambient volatile organic compounds and lung cancer in Toronto, Ontario, Canada. Am J Epidemiol. 2014; 179:443-451. [PubMed: 24287467]

[44]. Cesaroni G, Badaloni C, Gariazzo C, et al. Long-term exposure to urban air pollution and mortality in a cohort of more than a million adults in Rome. Environ Health Perspect. 2013; 121:324-331. [PubMed: 23308401] 
[45]. Jerrett M, Burnett RT, Beckerman BS, et al. Spatial analysis of air pollution and mortality in California. Am J Respir Crit Care Med. 2013; 188:593-599. [PubMed: 23805824]

[46]. Hart JE, Spiegelman D, Beelen R, et al. Long-Term Ambient Residential Traffic-Related Exposures and Measurement Error-Adjusted Risk of Incident Lung Cancer in the Netherlands Cohort Study on Diet and Cancer. Environ Health Perspect. 2015; 123:860-866. [PubMed: 25816363]

[47]*. Puett RC, Hart JE, Yanosky JD, et al. Particulate matter air pollution exposure, distance to road, and incident lung cancer in the nurses' health study cohort. Environ Health Perspect. 2014; 122:926-932. [PubMed: 24911062]

[48]. Hamra GB, Guha N, Cohen A, et al. Outdoor particulate matter exposure and lung cancer: a systematic review and meta-analysis. Environ Health Perspect. 2014; 122:906-911. [PubMed: 24911630]

[49]. Hystad P, Demers PA, Johnson KC, et al. Long-term residential exposure to air pollution and lung cancer risk. Epidemiology. 2013; 24:762-772. [PubMed: 23676262]

[50]. Koh DH, Kong HJ, Oh CM, et al. Lung cancer risk in professional drivers in Korea: a population-based proportionate cancer incidence ratio study. J Occup Health. 2015

[51]. Tsoi CT, Tse LA. Professional drivers and lung cancer: a systematic review and meta-analysis. Occup Environ Med. 2012; 69:831-836. [PubMed: 22767869]

[52]. HEI Collaborative Working Group on Air Pollution P; Health in Ho Chi Minh C. Le TG, et al. Effects of short-term exposure to air pollution on hospital admissions of young children for acute lower respiratory infections in Ho Chi Minh City, Vietnam. Res Rep Health Eff Inst. 2012:5-72. discussion 73-83. [PubMed: 22849236]

[53]**. Darrow LA, Klein M, Flanders WD, et al. Air pollution and acute respiratory infections among children 0-4 years of age: an 18-year time-series study. Am J Epidemiol. 2014; 180:968-977. [PubMed: 25324558] 


\section{Key points}

- $\quad$ Almost nine of ten individuals living in urban areas worldwide are affected by air pollution.

- $\quad$ The lack of a fully developed pulmonary metabolic capacity in children make them more susceptible to air pollutants compared to adults.

- $\quad$ Air pollution continues to be associated with reduced lung function and enhanced airway reactivity in children suffering from asthma.

- $\quad$ Prolonged exposure to air pollution exposes children to an increased risk of developing asthma.

- $\quad$ Air pollution and ambient exposure to nitrogen oxides, $\mathrm{SO}_{2}$, and $\mathrm{PM}_{2.5}$ from vehicle emissions significantly increase the risk of lung cancer.

- $\quad$ Short-term episodes of air pollution in children can heighten respiratory infection symptoms and the frequency of emergency room visits. 